\title{
¿UTILIZAN LOS ALUMNOS \\ ESQUEMAS CONCEPTUALES \\ EN LA INTERPRETACIÓN DEL SONIDO?
}

\author{
SAURA LLAMAS, OCTAVIO y DE PRO BUENO, ANTONIO \\ Departamento de Didáctica de las Ciencias Experimentales. Facultad de Educación. \\ Universidad de Murcia.
}

\begin{abstract}
SUMMARY
The origin of this work can be traced to investigations that have centred on the students' previous knowledge that conditions their learning process. There are, however, two aspects which must be taken into account: firstly, to know about the students' previous ideas should no be considered as an end in itself but as the starting point towards deliberate intervention and, secondly, when someone uses his knowledge, he does it with conceptual structures and with certain strategies related to them.

Our work concentrates on the identification of the students' ideas (both conceptual and procedural) about one of the few areas to which not many contributions have been made: the learning of sound. We attempt to identify the possible schemes the students use in their interpretation of aspects related to their everyday life. Finally, we establish certain implications for the teaching of these contents in compulsory secondary Education.
\end{abstract}

\section{INTRODUCCIÓN}

Cualquier modelo didáctico tiene como fundamento una teoría psicológica que trata de explicar cómo se produce el aprendizaje. Así, el modelo tecnológico utilizó las aportaciones de las psicologías conductista o asociacionista y los métodos activos tenían como referencia las contribuciones de la psicología evolutiva. Ahora bien, desde la década de los ochenta, si hay una teoría psicológica arraigada en la didáctica de las ciencias, es el constructivismo con «todas sus modalidades» (Posner et al., 1982; Hodson, 1985; Osborne y Wittrok, 1985; Driver, 1988; Novak, 1988; Giordan, 1989...).

El origen de este marco teórico habría que buscarlo en numerosas investigaciones sobre las características de los conocimientos que permiten al ser humano predecir, controlar, explicar, interpretar... la realidad (Pozo et al., 1991; Pozo, 1992). De ahí la creencia compartida sobre la importancia que tiene considerar las ideas de los alumnos en la planificación de propuestas didácticas, la dificultad para utilizarlas intencionadamente en las actividades concretas que se desarrollan en el aula o la necesidad de ajustar el estilo de enseñanza y el que utiliza el estudiante en su aprendizaje (Kempa, 1991). Además, si consideramos que la educación implica un contexto de comunicación, habría que tener presentes las interferencias existentes entre el lenguaje cotidiano y la terminología científica (Llorens et al., 1989), que podríamos hacer extensible a la desconexión entre el contexto social y el escolar.

Algunos profesores no comprenden que sus alumnos no aprendan lo que ellos «explican claramente» en el aula e, incluso, a veces les culpan de la situación. En estos casos creemos que se ignoran las diferencias que existen entre 


\section{INVESTIGACIÓN DIDÁCTICA}

el conocimiento de los científicos (más próximo teóricamente al de los profesores) y el de los estudiantes. Compartimos las ideas de Pozo (1992) cuando afirma que los primeros buscan la verdad y los otros la utilidad, que el grado de implicación en la defensa de sus teorías es diferente, que el desarrollo madurativo e intelectual es distinto y que el alumno no elige libremente estudiar ciencias... Pero, sobre todo, se podría pensar que estos profesores vuelven la espalda a muchas aportaciones respecto a cómo se produce el aprendizaje.

Aunque cada vez un mayor número de docentes se declaran «constructivistas», puede resultar preocupante que, en muchos casos, se ha identificado el constructivismo con el estudio de los conocimientos iniciales, lo cual ha distorsionado algunas percepciones sobre dicho modelo didáctico (Marín y Jiménez, 1992). En efecto, conocer las ideas previas no es un fin en sí mismo sino un punto de partida de cara a una intervención intencionada; lo realmente sustancial no es identificarlas sino saber por qué se originan y cómo se pueden trabajar para provocar o favorecer el aprendizaje de los alumnos (Clough y Driver, 1986).

Pero, además, otros autores ponen de manifiesto que para aprender es preciso establecer relaciones; que existen unos conceptos (inclusores) que son los generadores de los demás y que es posible establecer una jerarquía conceptual entre ellos. Esto nos lleva a pensar que, cuando una persona utiliza su conocimiento, lo hace con sus estructuras conceptuales y con unas estrategias relacionadas con éstas (Novak, 1988).

Sin embargo, la mayoría de los estudios se han centrado en el diagnóstico sobre ideas aisladas y pocas veces se realizan investigaciones sobre conceptos relacionados o estructuras conceptuales (Otero, 1990). Pensamos que los alumnos disponen de unas teorías, creencias, ideas... más o menos estructuradas, que tratamos de aproximar a las científicas. Por lo tanto, resulta muy importante identificarlas, conocer su evolución... y que los propios estudiantes sean conscientes de que estas cambian con el aprendizaje.

Nuestro trabajo se va a centrar en la identificación de las ideas de los alumnos sobre uno de los pocos ámbitos de la didáctica de las ciencias experimentales en el que no existen muchas aportaciones: el aprendizaje del sonido. Posteriormente, trataremos de reconocer los posibles esquemas que utilizan en la interpretación de hechos o fenómenos de su vida cotidiana. Por último, estableceremos algunas implicaciones para la enseñanza de estos contenidos en la educación secundaria obligatoria.

\section{REVISIÓN DE LA LITERATURA CIENTÍFICA}

Como hemos comentado, los estudios desarrollados en este ámbito del conocimiento han sido escasos; este hecho ya ha sido resaltado por Perales (1997). No obstante, en el cuadro I aparecen sintetizados algunos trabajos que han sido referentes en nuestra investigación.

Hay que resaltar que en ninguno de ellos se abordan conceptos de gran relevancia y cotidianidad; por ejemplo, el eco, la reverberación, la audición, la contaminación acústica... Se centran sobre todo en los niveles superiores del sistema educativo; ¿podría interpretarse que son contenidos que no pueden abordarse en la educación básica y obligatoria de un ciudadano?

Al respecto quisiéramos destacar que la mayoría de los alumnos de educación secundaria obligatoria han tenido experiencias relacionadas con estos temas: cuando arro-

Cuadro I

Trabajos sobre ondas y sonido.

\begin{tabular}{|l|l|c|}
\hline Ámbito del trabajo & Nivel educativo & Autores \\
\hline $\begin{array}{l}\text { Conceptualización del sonido desde una perspectiva microscópica } \\
\text { por los alumnos a partir de hechos cotidianos }\end{array}$ & Universidad & $\begin{array}{c}\text { Linder y Erikson } \\
(1989)\end{array}$ \\
\hline $\begin{array}{l}\text { Propagación del sonido y factores que los estudiantes consideran } \\
\text { relevantes en su velocidad; implicaciones para su enseñanza }\end{array}$ & Universidad & Linder (1993) \\
\hline $\begin{array}{l}\text { Propagación de señales en una cuerda y las dificultades que los } \\
\text { alumnos encuentran en el estudio de su velocidad, la influencia } \\
\text { del medio y su evolución con el tiempo }\end{array}$ & $\begin{array}{l}\text { Bachillerato } \\
\text { Universidad }\end{array}$ & Maurines (1992a) \\
\hline $\begin{array}{l}\text { Propagación de señales mecánicas: dificultades de una situación } \\
\text { de varias variables, el «capital» como soporte del razonamiento } \\
\text { espontáneo y dependencias funcionales }\end{array}$ & $\begin{array}{l}\text { Bachillerato } \\
\text { Universidad }\end{array}$ & Maurines (1992b) \\
\hline
\end{tabular}


jan piedras al agua de un estanque, cuando producen ondas mecánicas con una cuerda, cuando tocan instrumentos musicales... Estas situaciones generan unos aprendizajes -acertados o equivocados- y, desde luego, facilitan que se perfilen ideas personales para la interpretación de fenómenos de su realidad más próxima (López et al., 1997).

Por otro lado, numerosos autores reconocen la decisiva importancia que hoy día suponen las ondas en el avance de la física y la imposibilidad de eludir su presencia desde el punto de vista científico:

«[...] la cuestión nueva e importante es que por primera vez se considera el movimiento de algo que no es materia, sino energía, que se propaga a través de la materia» (Einstein e Infeld, 1961).

«Uno de los avances sobresalientes del siglo XX ha sido el descubrimiento de que toda la materia está dotada de propiedades ondulatorias» (Sears, 1973).

«El mundo está lleno de ondas: ondas sonoras; ondas mecánicas, tales como una onda en una cuerda; ondas sísmicas; ondas de choque, generadas por aviones supersónicos, y ondas electromagnéticas, como la luz visible, las ondas de radio, las señales de televisión y los rayos

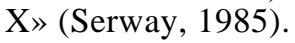

Pero, además, la acústica tiene cada vez una importancia más decisiva desde el punto de vista social: influye en aspectos esenciales de la calidad de vida de los seres humanos, de su cultura musical e, incluso, en el conocimiento fisiológico de su propio cuerpo. Por todo ello, la inclusión de estos contenidos en la ESO nos parece adecuada, aunque puede encontrarse con dos grandes problemas: la escasa tradición de su presencia en los programas de ciencias y el desconocimiento de algunos profesores sobre esta materia.

\section{INSTRUMENTOS DE RECOGIDA DE INFORMACIÓN}

Cuando se investiga sobre qué saben los alumnos o cómo utilizan sus aprendizajes en diferentes contextos, siempre surge el mismo problema: cómo conseguir datos útiles, válidos y fiables, que realmente representen sus ideas, creencias, conocimientos. No conocemos una solución universal a este tema, pero nuestra experiencia nos aconseja que se utilicen «técnicas mixtas» de recogida de información; por ejemplo, cuestionarios escritos y entrevistas.

Para el estudio de las ideas de los alumnos respecto al sonido, hemos utilizado unas pruebas que abarcan contenidos conceptuales y procedimentales (Saura, 1996). La distinción establecida es analítica, ya que existe una gran interrelación entre ellos. De hecho, la mayor importancia que se ha venido dando a los conceptuales creemos que es uno de los factores que ha propiciado el bajo rendimiento en las asignaturas de ciencias, la falta de interés por su estudio, y el mantenimiento de una visión distorsionada y poco útil, tanto de la ciencia como de los científicos. Creemos necesario la inclusión intencionada de los contenidos procedimentales en la planificación de la acción docente y en la intervención en el aula (Pro, 1998).

Las pruebas fueron elaboradas seleccionando preguntas y actividades de libros de texto de diversos niveles educativos. Las cuestiones tenían diferentes formatos, pero la característica común a todas ellas era que no sólo se les pedía una respuesta sino que debían justificarla.

Es cierto que, cuando se utilizan «indiscriminadamente» cuestionarios escritos, no siempre las contestaciones responden a lo que el alumno sabe; algunas veces porque éste se despreocupa por la tarea que está realizando, otras porque aparecen los «reflejos académicos» que le exigen una acomodación o matización de lo que piensa, en ocasiones porque le resulta difícil expresarse, etc. En nuestro caso, optamos por pasar, en primer lugar, un cuestionario escrito que les sirviera para reflexionar y explicitar sus razonamientos. Aunque nos sorprendió que las respuestas, en general, eran amplias y contenían muchas opiniones y argumentaciones, posteriormente se realizaron entrevistas personales para completar - no para cuestionar, distorsionar o condicionar- sus contestaciones. Los datos que utilizaremos en este trabajo corresponden a la síntesis de ambos procesos, que lógicamente no consideramos independientes.

Los alumnos que contestaron las pruebas fueron 43 y pertenecían al $2^{\circ}$ curso de electricidad y electrónica de un instituto de formación profesional de Molina del Segura (Murcia). Aunque no es un objetivo de este trabajo el estudio de la dependencia con variables sociológicas, podemos señalar algunas características que permiten contextualizar la muestra:

a) 15 alumnos tenían 15 años; 16 tenían 16 años; 6 tenían 17 años y otros 6 tenían 18 .

b) Todos tenían su residencia habitual en Molina o en localidades muy próximas; no obstante, existía un preocupante absentismo académico en la mayoría de las asignaturas.

c) 39 de los 43 tenían el graduado escolar; 15 eran repetidores de $2^{\circ}$ curso.

d) Los estudios de los padres eran primarios en 32 casos, medios en 10 y superiores en un solo caso; los de la madre eran primarios en 40 casos, medios en 3 y no había ninguna con estudios universitarios.

\section{Prueba de contenidos conceptuales}

La prueba sobre contenidos conceptuales relacionados con las ondas y el sonido constaba de nueve ítems. Nuestro objetivo, como profesores, no sólo era detectar 
Cuadro II

Prueba de contenidos conceptuales.

\begin{tabular}{|c|c|c|c|}
\hline Ítem & \multicolumn{2}{|c|}{ Conceptos implicados } & Esquemas \\
\hline 1. Pon cinco ejemplos de movimientos ondulatorios. & - Onda & & $\begin{array}{l}\text { Magnitudes } \\
\text { ondulatorias }\end{array}$ \\
\hline $\begin{array}{l}\text { 2. En un movimiento ondulatorio, ¿hay transporte } \\
\text { de materia, de energía, de ambas o de ninguna } \\
\text { de ellas? Explica tu respuesta. }\end{array}$ & $\begin{array}{l}\text { - Onda } \\
\text { - Energía } \\
\text { - Materia }\end{array}$ & $\begin{array}{l}\text { - Propagación de ondas } \\
\text { - Modelo de ondas }\end{array}$ & $\begin{array}{l}\text { Magnitudes } \\
\text { ondulatorias }\end{array}$ \\
\hline $\begin{array}{l}\text { 3. Cuando escuchas la radio, seguro que has oído } \\
\text { hablar de frecuencia y de longitud de onda. } \\
\text { ¿Qué significan para ti esos términos? }\end{array}$ & - Frecuencia & - Longitud de onda & $\begin{array}{l}\text { Magnitudes } \\
\text { ondulatorias }\end{array}$ \\
\hline $\begin{array}{l}\text { 4. ¿Cuál crees que es la velocidad del sonido } \\
\text { en el vacío? ¿Crees que es superior a la velocidad } \\
\text { del sonido en el agua? Por favor, explica tu respuesta. }\end{array}$ & $\begin{array}{l}\text { - Vacío } \\
\text { - Propagación } \\
\quad \text { del sonido }\end{array}$ & $\begin{array}{l}\text { - Velocidad del sonido } \\
\text { - Modelo de ondas }\end{array}$ & $\begin{array}{l}\text { Propagación } \\
\text { del sonido }\end{array}$ \\
\hline $\begin{array}{l}\text { 5. Cuando un avión «rompe la barrera del sonido», } \\
\text { se produce un estruendo, rompiéndose incluso } \\
\text { los cristales de algunas ventanas. } \\
\text { ¿Cómo podrías explicar este hecho? }\end{array}$ & $\begin{array}{l}\text { - Onda } \\
\text { - Propagación } \\
\text { del sonido }\end{array}$ & $\begin{array}{l}\text { - Velocidad del sonido } \\
\text { - Modelo de ondas }\end{array}$ & $\begin{array}{l}\text { Propagación } \\
\text { del sonido }\end{array}$ \\
\hline $\begin{array}{l}\text { 6. ¿De qué factores depende la intensidad de un sonido? } \\
\text { ¿De la temperatura, de la densidad del medio, de las } \\
\text { características de la onda o de la masa del cuerpo } \\
\text { que vibra? Explica tu respuesta. }\end{array}$ & $\begin{array}{l}\text { - Intensidad del sonido } \\
\text { - Densidad } \\
\text { - Temperatura }\end{array}$ & $\begin{array}{l}\text { - Onda } \\
\text { - Masa }\end{array}$ & $\begin{array}{l}\text { Magnitudes } \\
\text { ondulatorias }\end{array}$ \\
\hline $\begin{array}{l}\text { 7. Seguro que has estado en algún sitio en que hubiera eco. } \\
\text { ¿Podrías decir qué es el eco? ¿Es una propiedad de } \\
\text { las montañas, una cualidad del sonido, un fenómeno } \\
\text { de reflexión o uno de amortiguación? } \\
\text { Por favor, explica tu respuesta. }\end{array}$ & $\begin{array}{l}\text { - Propagación del sonido } \\
\text { - Cualidad del sonido } \\
\text { - Eco }\end{array}$ & $\begin{array}{l}\text { - Reflexión del sonido } \\
\text { - Amortiguación }\end{array}$ & $\begin{array}{l}\text { Reflexión } \\
\text { del sonido }\end{array}$ \\
\hline $\begin{array}{l}\text { 8. Se pulsan con la misma fuerza dos violines } \\
\text { exactamente iguales, en el mismo sitio de la cuerda. } \\
\text { ¿En qué se diferencian los sonidos correspondientes? } \\
\text { ¿En la intensidad, en el tono, en el timbre o en nada? } \\
\text { Explica tu respuesta. }\end{array}$ & $\begin{array}{l}\text { - Intensidad del sonido } \\
\text { - Tono } \\
\text { - Timbre }\end{array}$ & $\begin{array}{l}\text { - Amplitud } \\
\text { - Frecuencia }\end{array}$ & $\begin{array}{l}\text { Magnitudes } \\
\text { ondulatorias }\end{array}$ \\
\hline $\begin{array}{l}\text { 9. ¿Es verdad que los perros oyen mejor que las personas? } \\
\text { Di todo lo que sepas sobre el asunto. }\end{array}$ & $\begin{array}{l}\text { - Receptor } \\
\text { - Emisor } \\
\text { - Intensidad del sonido }\end{array}$ & $\begin{array}{l}\text { - Frecuencia } \\
\text { - Umbral de audición }\end{array}$ & $\begin{array}{l}\text { Magnitudes } \\
\text { ondulatorias }\end{array}$ \\
\hline
\end{tabular}

los conocimientos que tenían los alumnos, sino también disponer de una información relevante para tomar decisiones respecto a la planificación de una propuesta para la enseñanza del sonido y para nuestra intervención en el aula (Saura, 1996).

El cuadro II trata de facilitar su descripción. En él figuran tres filas; la primera hace referencia a la formulación del ítem correspondiente, la segunda a los conceptos implicados y la tercera a los esquemas conceptuales a los que nos referiremos más adelante. Estos dos últimos aspectos están identificados desde la perspectiva de los investigadores, lo que no siempre coincide con la de los alumnos.

Lo primero que hicimos con las respuestas fue categorizarlas según una clave de vaciado. Esta tabulación inicial trataba de agrupar las contestaciones similares, sin perder información de las respuestas originales. Ello nos permite un estudio descriptivo de los conocimientos conceptuales de nuestros alumnos, en la línea de otros trabajos de similares características. 


\section{Prueba de contenidos procedimentales}

La prueba sobre contenidos procedimentales constaba de cuatro ítems. De forma análoga a la anterior hemos utilizado el cuadro III para facilitar su descripción. En él aparecen nuevamente tres filas; la primera hace referencia a la cuestión correspondiente, la segunda a los contenidos procedimentales implícitos y la tercera a los conceptos implicados en ese ítem, desde la perspectiva de los investigadores.

De manera similar a la prueba de contenidos conceptuales, elaboramos una clave de vaciado que nos permitiera la categorización de los respuestas obtenidas y que facilitara el estudio descriptivo correspondiente.

\section{Estrategias para determinar los esquemas conceptuales}

$\mathrm{Si}$, como hemos dicho, consideramos que los alumnos utilizan esquemas, más o menos estructurados, en la interpretación de la realidad, parece conveniente inferir qué relaciones establecen entre sus concepciones e ideas científicas. Al conjunto de todas las relaciones conceptuales o proposicionales que utilizan los alumnos en sus opiniones y argumentaciones, los denominamos esquemas conceptuales.
Los esquemas no han sido elaborados directamente por ellos; los hemos inferido nosotros a partir de sus respuestas -escritas y de las entrevistas- a las preguntas en las que estaba implicado el tópico en cuestión. Por ejemplo, en el caso del esquema de la propagación del sonido, hemos utilizado preferentemente las explicaciones que han dado a las cuestiones 4, 5 y 6 de la prueba conceptual, y a las cuestiones $1 \mathrm{p}, 2 \mathrm{p}$ y $3 \mathrm{p}$, en la procedimental, aunque lógicamente no hemos ignorado las respuestas a otros ítems, que a priori parecían, desde nuestra perspectiva, no tener conexión con el esquema. Insistimos en que no siempre hay coincidencias entre los contenidos que los investigadores suponemos que serán utilizados y los que realmente ponen en juego o activan los alumnos.

En el cuadro IV aparecen especificados aquellos ítems que han guardado una relación más relevante con los esquemas de referencia y las denominaciones asignadas a los que hemos encontrado en nuestra muestra. Lógicamente no pretendemos la universalización ni la generalización de los mismos en otros contextos.

Podríamos sintetizar la secuencia de pasos realizados de la siguiente manera:

a) A partir de las contestaciones, se realizó una lista individual con todas las relaciones conceptuales que

Cuadro III

Prueba de contenidos procedimentales.

\begin{tabular}{|c|c|c|}
\hline Ítem & Procedimientos implicados & Conceptos implicados \\
\hline $\begin{array}{l}\text { 1p. Se sabe que es posible escuchar lo que dice una persona } \\
\text { a } 1 \mathrm{~km} \text { de distancia si el viento está a favor (sobre todo, } \\
\text { si estamos en invierno). Elabora una hipótesis } \\
\text { para explicar este hecho. }\end{array}$ & $\begin{array}{l}\text { - Identificación del problema } \\
\text { - Formulación de hipótesis }\end{array}$ & $\begin{array}{l}\text { - Propagación del sonido } \\
\text { - Distancia } \\
\text { - Velocidad } \\
\text { - Temperatura } \\
\text { - Densidad }\end{array}$ \\
\hline $\begin{array}{l}\text { 2p. Se sabe que es posible escuchar lo que dice una persona } \\
\text { a } 1 \mathrm{~km} \text { de distancia si el viento está a favor (sobre todo, } \\
\text { si estamos en invierno). Diseña una experiencia } \\
\text { para comprobarlo. }\end{array}$ & $\begin{array}{l}\text { - Diseño de experiencias } \\
\text { - Control de variables }\end{array}$ & $\begin{array}{l}\text { - Propagación del sonido } \\
\text { - Distancia } \\
\text { - Velocidad } \\
\text { - Temperatura } \\
\text { - Densidad }\end{array}$ \\
\hline $\begin{array}{l}\text { 3p. La gente del campo, cuando ve una tormenta y quiere } \\
\text { saber a cuántos km se encuentra, hace lo siguiente: } \\
\text { Espera a que caiga un rayo, cuenta los segundos que pasan } \\
\text { hasta que oyen el trueno, y divide esos segundos entre tres. } \\
\text { ¿Crees que es correcto el procedimiento desde un punto } \\
\text { de vista científico? Explica tu respuesta. }\end{array}$ & $\begin{array}{l}\text { - Identificación del problema } \\
\text { - Análisis de datos } \\
\text { - Establecimiento } \\
\text { de conclusiones }\end{array}$ & $\begin{array}{l}\text { - Propagación de luz y sonido } \\
\text { - Velocidad de luz y sonido } \\
\text { - Distancia } \\
\text { - Tiempo } \\
\text { - Movimiento rectilíneo } \\
\text { y uniforme }\end{array}$ \\
\hline $\begin{array}{l}\text { 4p. ¿Podrías diseñar una experiencia para demostrar } \\
\text { que, cuando tiramos una piedra a un lago, se produce } \\
\text { una onda? }\end{array}$ & - Diseño de experiencias & $\begin{array}{l}\text { - Onda } \\
\text { - Modelo de ondas }\end{array}$ \\
\hline
\end{tabular}


Cuadro IV

Esquemas conceptuales.

\begin{tabular}{|l|l|l|}
\hline Esquema & Ítems prueba & Tipo de esquemas encontrados \\
\hline Magnitudes ondulatorias & $1,2,3,6,8,9$ y $4 \mathrm{p}$ & $\begin{array}{l}\text { MO-1, MO-1a, MO-1b, MO-2, MO-3, MO-3a, MO-4, } \\
\text { MO-4a, MO-4b y MO-5 }\end{array}$ \\
\hline Propagación del sonido & $4,5,6,1 \mathrm{p}, 2 \mathrm{p}$ y $3 \mathrm{p}$ & PS-1, PS-2, PS-3, PS-4, PS-5 y PS-6 \\
\hline Reflexión del sonido & 5,7 y $4 \mathrm{p}$ & RS-1, RS-2, RS-2a, RS-3, RS-4 y RS-5 \\
\hline
\end{tabular}

cada alumno ponía de manifiesto a lo largo de las pruebas.

b) Se identificaron las ideas y proposiciones que fueron utilizadas reiteradamente: varias veces o en varios ítems; si existía esta reiteración, pensamos que estaba asentada suficientemente y que podía formar parte activa, y no sólo anecdótica, de los razonamientos utilizados.

c) Identificadas las proposiciones correspondientes a cada alumno, se agruparon en función de su pertenencia a los campos en que fijamos nuestra atención (magnitudes ondulatorias, propagación del sonido y reflexión del sonido).

d) Para no arrastrar el conjunto de las proposiciones en nuestra descripción de resultados, tratamos de representarlas mediante mapas conceptuales.

Como era previsible, no siempre ha sido posible encontrar un esquema característico, a veces por la falta de consistencia de los argumentos de los entrevistados y otras porque no hemos sido capaces de encontrarlos con los instrumentos y técnicas utilizados. Sin embargo, lo que realmente nos llamó la atención es que estas hipotéticas estructuras no eran casos únicos sino que se repetían, con escasas diferencias, en varios alumnos y que, además, era factible una cierta ordenación en función de su mayor o menor cientificidad, coherencia y complejidad, como veremos más adelante.

\section{RESULTADOS CORRESPONDIENTES A LA PRUEBA DE CONTENIDOS CONCEPTUALES}

La primera descripción de los resultados de la prueba de contenidos conceptuales la hemos hecho ítem a ítem. Hay que señalar previamente que la mayoría contestó a casi todas las cuestiones, por lo que podemos suponer que no existían problemas de comprensión, de falta de interés o contextos inadecuados para la comunicación. Vamos a sintetizar las características más relevantes de las respuestas que dieron los alumnos; en algunos casos, hemos incluido sus contestaciones textuales para facilitar al lector una información más completa.

a) Respecto al ítem 1: Ejemplos de movimientos ondulatorios

- Pusieron 121 ejemplos, lo que equivale a casi tres por alumno; de ellos, 102 parecen proyectar la existencia de experiencias y conocimientos iniciales en el tema.

- Los ejemplos más repetidos se referían a ondas materiales (66/102); el sonido apareció de manera explícita o implícita en muchos casos (la tos, la voz, el ruido, el eco, los golpes, etc.).

- Las alusiones más frecuentes a las electromagnéticas (27/102) fueron las asociadas a medios de comunicación (ondas de radio, de televisión, del walkman...) o las luminosas (luz de las bombillas, láser...).

- Algunos confunden las ondas con el generador de las mismas: antena, emisora, cuerdas bucales, etc.

- Hubo ejemplos extraños que eran justificados por la periodicidad (una aguja de reloj, una sirena de policía o de bomberos...) o por la forma (el arco iris, el agua, el mar, los pájaros moviendo las alas o, incluso, las patatas Matutano).

\section{b) Respecto al ítem 2: Trasporte en un movimiento} ondulatorio

- Muchos alumnos (18/43) señalaban en el cuestionario escrito que un movimiento ondulatorio lleva implícito un transporte de energía; otros creían que se produce un transporte de materia (13/43); y algunos consideraban que no hay transporte ni de materia ni de energía (12/43).

- La mayoría, con independencia de la opción elegida, no fueron capaces de justificarla ni por escrito ni en la entrevista posterior. Sin embargo, algunos (7/43) aportaron argumentos interesantes de cara a una intervención didáctica: 
«Las ondas necesitan energía para poder moverse en el espacio.»

«Cuando un receptor capta una onda, éste capta la energía que transporta esa onda [...].»

«[...] debido a que estas ondas están produciendo un movimiento.»

«No puede ser un transporte de materia porque las ondas no están formadas ni compuestas por nada [...].»

La ausencia o la ambigüedad de las justificaciones nos hace suponer que, en general, no tienen un conocimiento -acertado o equivocado- de los conceptos implicados, lo que resulta lógico por la gran complejidad de los mismos. Creemos que éste puede ser uno de los muchos ejemplos en los que se debe hablar de ausencia de información más que de errores o ideas alternativas.

\section{c) Respecto al ítem 3: Frecuencia y longitud de onda de una radio}

- De los 36 alumnos que contestaron a la parte que trataba de la frecuencia, 8 establecían una relación entre el número de ciclos o de «ondas» y el tiempo, o entre sus unidades. No obstante, en 14 casos la identificaron con el canal que sintonizas y 4 con una emisora de radio, porcentajes que apoyan el carácter extraescolar de algunas de las concepciones.

- El apartado que trataba de la longitud de onda fue contestado por 27; en un caso, se hablaba de «distancia entre crestas». Sin embargo, lo más frecuente (12/27) fue identificarla con el alcance de la onda.

- Algunos (4/43) manifestaron que la frecuencia y la longitud de onda eran lo mismo y, en otros casos, las confundían con otras magnitudes ondulatorias (velocidad de propagación y amplitud).

Habría que destacar la sorprendente facilidad que tienen los alumnos en la utilización de estos conceptos, con independencia de su «ortodoxia científica». Pensamos que no se pueden ni deben ignorar estas situaciones de cara a la planificación de una propuesta didáctica o de unas actividades de enseñanza, ya que un planteamiento metodológico inadecuado puede desaprovechar una circunstancia tan interesante, al menos potencialmente.

d) Respecto al ítem 4: Velocidad del sonido en el vacío y en el agua

- De los alumnos que contestaron a la pregunta (34/43), tres reconocen la necesidad de un medio material y proyectan un modelo de propagación de ondas materiales que consideramos bastante adecuado para este nivel educativo:

«En el vacío no se puede propagar el sonido; necesitamos aire, moléculas que puedan transmitir una perturbación.»
«En el vacío no tiene ninguna velocidad, ya que se encontraría sin aire y no se podría desplazar, por lo que no es superior a la velocidad en el agua, ya que en el agua se desplaza.»

- A estos podríamos unir otros cinco que, sin establecer explícitamente el valor de la velocidad del sonido en el vacío, parece que utilizan un modelo de propagación similar:

«En el vacío no hay sonido y no se puede propagar, y en el agua lo que se produce es un movimiento de sus partículas.»

«No sé cuál es la velocidad del sonido en el vacío, pero no creo que sea mayor que la velocidad del sonido en el agua porque en el agua los átomos están más unidos y, por lo tanto, es más fácil pasar.»

- Un porcentaje alto (23/34) deja entrever en sus respuestas la utilización de un modelo interpretativo de tipo corpuscular. Defienden que la velocidad del sonido en el agua es menor que en el vacío; en dicho medio, bien sea por la resistencia o por la densidad, manifiestan que la dificultad de propagación es mayor $\mathrm{y}$, por tanto, la velocidad será menor.

\section{e) Respecto al ítem 5: Avión y barrera del sonido}

- Un número mayor que en otros ítems de la prueba no contestaron la pregunta (16/43); además, hay que añadir otros (10/43) que no responden realmente:

«Los cristales se rompen porque el avión sobrepasa la velocidad del sonido.»

«[...] porque el avión va a más velocidad de la que le permite la barrera del sonido.»

- Hay quienes utilizan modelos interpretativos que no hemos sabido clarificar (4/43):

«[...] porque el avión produce ondas muy potentes.»

«[...] porque pasa lo mismo que cuando vas en bici y te pasa cerca una camión y te tira hacia un lado.»

«[...] porque, al superar la barrera del sonido, se produce una serie de cambios en el sonido que hace que se mueva más rápido.»

- El nivel de las respuestas no nos ha permitido sacar mucha información; sólo 10 aportan ideas sueltas (producción de nuevas ondas, diferentes velocidades de propagación, choque de ondas...):

«[...] porque el avión va a más velocidad que la del sonido y eso produce como un gran choque que rompe algunos cristales.»

«[...] porque va más rápido que el sonido que produce su avión y eso produce un choque entre ondas, que es lo que nosotros oímos, ese estruendo.» 
Habría que añadir que, en muchas contestaciones, se relacionaba este fenómeno con la reflexión del sonido: al romper la barrera, aparecen ondas que rebotan en las superficies que encuentran y, si son frágiles, se rompen. Esta «reflexión destructiva» puede ser considerada coherente con otras argumentaciones dadas en otros ítems de la prueba referidos a la reflexión del sonido.

\section{f) Respecto al ítem 6: Dependencia de la intensidad de} un sonido

- Fue contestada por un gran número de alumnos (40/43). Algunos señalaron varias opciones, pues interpretaban que la intensidad dependía de diversos factores.

- La opción más elegida ha sido la que dice que la intensidad del sonido depende de las características de la onda (18/40). Un grupo equivalente $(16 / 40)$ cree que depende de la densidad del medio y otros (11/40) de la masa del cuerpo que vibra. Muy pocos alumnos (5/40) creen que depende de la temperatura.

El problema para los propósitos de nuestra investigación fue la ausencia o la escasez de argumentos ante las opciones que ellos habían elegido. Ni eran capaces de justificar su opción ni por qué habían rechazado otras; como si hubiera una elección más intuitiva que razonada. Esta situación se repitió en otras cuestiones que contenían en su formulación una gran carga de «conceptos académicos» (por ejemplo, en el ítem 2), lo que debe considerarse de cara a la formulación de cuestiones exploratorias.

En cualquier caso, se percibió la dificultad que tienen los alumnos para establecer relaciones causales entre variables o para la utilización de contenidos procedimentales con ellas relacionados. Esto resulta contradictorio con el currículo oficial de los niveles anteriores del sistema educativo; deberíamos revisar qué estamos enseñando, sobre todo aquellos profesores que tienen por bandera el estricto cumplimiento de los programas.

\section{g) Respecto al ítem 7: El eco}

- Ningún alumno cree que el eco sea una propiedad de las montañas y pocos (3/41) que sea una cualidad del sonido. Las demás respuestas se pueden encuadrar en dos grandes grupos.

- Por un lado, hay 18 que dicen que es un fenómeno de amortiguación del sonido, pero casi la totalidad lo justifican con argumentos próximos a la reflexión (15/18):

«Es cuando tú mandas un sonido, la onda rebota y vuelve a ti.»

«Al emitirse una onda de sonido, ésta al chocar con un cuerpo se refleja y produce el eco con menos frecuencia.»

«Creo que es igual que una pelota, que, cuando la tiras a la pared, vuelve pero con menos fuerza, por eso, cuando oímos el final de una palabra que hemos dicho, es porque la palabra la hemos terminado con más intensidad.

- Otros 20 consideran que es un fenómeno de reflexión, justificándolo también con expresiones como:

«[...] porque las ondas del sonido al llegar a la montaña rebotan en ella y vuelven hacia atrás.»

«[...] oyes el sonido, pasa, rebota en una pared gruesa, no pasa por la pared, rebota y vuelves a oírla.»

«[... al lanzar tus ondas, rebotan en la pared o en la montaña y vuelven a ti y las escuchas.»

«[...] el sonido se amortigua y rebota contra las rocas.»

Paradójicamente las justificaciones de ambos grupos parecen similares (hacen referencia a los rebotes de las ondas), lo que inducía a pensar que sus diferencias eran más semánticas que conceptuales. No obstante, al profundizar en sus contestaciones, apareció un número importante (12/43) que justificaban su elección porque (el eco) producía un sonido más bajo; de ellos, 11 habían elegido la opción amortiguadora y uno la «reflexiva».

Además, hay que señalar que un grupo importante (11/43) no sólo identifican el eco como un fenómeno de reflexión del sonido sino que reconocen que éste se produce en determinadas condiciones, aunque sin llegar a establecer las leyes. De ellos, hay quienes hablan de un desfase temporal entre las ondas incidentes y reflejadas en su audición (7/11).

\section{h) Respecto al ítem 8: Diferencias entre dos violines}

- La mayoría (23/43) cree que no se diferencian, y lo justifican diciendo que, si los violines son iguales y se pulsan de la misma manera, producirán la misma onda.

- Otros 7 alumnos creen que los sonidos se diferencian en la intensidad, a pesar de que el enunciado de la pregunta dice claramente que se pulsan con la misma fuerza. (¿No establecen relación entre la fuerza de pulsación y la intensidad o no han comprendido el texto?)

- Hay alumnos (6/43) que no nombran explícita o exclusivamente el timbre, pero dan una justificación que contempla implícitamente a esta cualidad del sonido:

«[...] porque no hay nada en el mundo que produzca ondas iguales.»

«[...] no hay dos violines iguales, siempre cambiarán.»

«[...] creo que es el tono y el timbre, ya que según el material de la cuerda y su grosor dependen estos dos factores...»

A la vista de los resultados, podemos afirmar que desconocen el significado científico del concepto de timbre pero que, en algunos casos, existe una experiencia previa que se puede y se debe aprovechar didácticamente. 
Sin embargo, lo que realmente nos preocupa es que no relacionan en sus justificaciones las magnitudes ondulatorias y las cualidades del sonido; se podría hablar, incluso, de temas diferentes. De hecho, en este ítem hay una presencia de argumentos musicales - parece que provienen de otras materias o cursos- que se utilizan muy localizadamente en otras respuestas a la prueba.

\section{i) Respecto al ítem 9: Audición de los perros}

- Muchos (36/43) contestaron la pregunta. En 4 casos, podemos observar y valorar la calidad de algunas argumentaciones:

«Creo que no oyen mejor que las personas, lo que pasa es que su oído está más desarrollado que el nuestro y captan una gama de frecuencias mayor que el nuestro, que es de $20 \mathrm{~Hz}$ a $20.000 \mathrm{~Hz}$.»

«[...] porque en las personas el sentido más desarrollado es el de la vista, entonces, el oído lo tenemos menos desarrollado. Por eso las personas oímos sonidos desde unos valores mínimos hasta unos valores máximos, si están inferior o superior a estos valores no lo oímos. Para los perros esos valores están más ampliados y, entonces, hay sonidos que nosotros no detectamos y ellos sí.»

«Las personas pueden oír a una frecuencia de $12 \mathrm{KHz}$ hasta $16 \mathrm{KHz}$ y los perros escuchan desde los $10 \mathrm{KHz}$ a una frecuencia mucho mayor que las personas.»

- Otros 7 aportan ideas menos estructuradas, pero utilizan el concepto de frecuencia como «eje conceptual» de la argumentación:

«Porque, cuando se sopla un pito para perros, las personas no lo oyen, porque va a una gran frecuencia, y, cuando hay un ruido, los primeros en reaccionar son los perros.»

«Yo no sé si los perros oyen mejor o peor que nosotros, lo que sí sé es que éstos oyen sonidos a diferentes frecuencias que nosotros. Hay sonidos que ellos oyen y nosotros no, y otros, al contrario.»

«Es que tienen más facilidad para captar sonidos agudos, que el oído humano no puede distinguir y los perros sí.»

«Yo creo que sí, por eso hay perros de caza que son capaces de oír el más pequeño ruido que el hombre no podría hacerlo nunca. Creo que es porque su oído capta muy bien sonidos de muy baja frecuencia al igual que las altas les cuesta. Ésa en mi opinión.»

- El resto (25/36) dan una respuesta superficial, atribuyéndoselo sencillamente a que el oído de los perros es más fino, está más desarrollado o es más sensible que el de los humanos, pero no explican por qué ocurre eso. Este tipo de comportamiento que denominamos responder sin responder se ha observado en varias ocasiones y obviamente dificulta la obtención de una información relevante para nuestros propósitos. No obstante, cree- mos que resulta consecuente con las características de la enseñanza recibida anteriormente.

Quisiéramos resaltar que, una vez más, el concepto de frecuencia parece tener más significado para los alumnos que el de longitud de onda. Por otro lado, nos sorprendió que, en esta relación entre intensidad y frecuencia, centraran sus justificaciones más en la segunda, cuando a priori parece que la primera es más intuitiva.

\section{RESULTADOS CORRESPONDIENTES A LA PRUEBA DE CONTENIDOS PROCEDI- MENTALES}

El estudio de los resultados de esta prueba lo hemos realizado con dos intenciones. Por un lado, queríamos realizar una descripción de las respuestas dadas por los alumnos respecto al aprendizaje de contenidos procedimentales relacionados con el tema, hecho no muy habitual en los estudios exploratorios. Por otro, como dijimos, las contestaciones han sido utilizadas en la elaboración de los esquemas conceptuales a los que hemos hecho referencia. En este apartado nos ocuparemos del primer objetivo, manteniendo el mismo estilo descriptivo que en la prueba de contenidos conceptuales.

\section{a) Respecto al ítem 1p: Hipótesis del sonido con viento a favor en invierno}

- Un pequeño grupo (6/37) de los que respondieron a la pregunta, incluyen en su formulación elementos que se pueden considerar fundamentales (establecimiento de una causalidad razonada, identificación de las variables coherentes con el razonamiento, explicitación de una posible interpretación, etc.):

«El viento transporta y lleva con mayor facilidad el sonido, la onda. Según la temperatura del ambiente, si es fría y húmeda, hay unas moléculas más unidas, por lo que se transmitirá la onda con mayor facilidad al chocar unas con otras.»

«[...] que al estar a favor del viento, la onda se propaga mejor que estando en contra. En invierno, la densidad del aire, hace mas propicio el movimiento de la onda.»

- Otros (22/37) se centran sólo en la relación con una de las variables que intervienen, normalmente en el viento a favor:

«[...] porque las ondas sonoras se verían empujadas por la fuerza del viento y avanzarían más.»

«Con el viento a favor, las ondas del sonido tardarían menos en llegar.»

«Si la persona habla en la misma dirección que la del viento, el viento ayudará a las ondas a que lleguen antes. Si se pone de espaldas, a las ondas les costará más llegar.» 
- Hay hipótesis un tanto confusas que no sabemos interpretar (7/37):

«Si hace viento las ondas se esparcen más lejos, y si no hace calor, no se pierden pronto.»

«[...] que puede ser que el viento transporte la voz expulsada de esa persona y la transporta hasta que se pierde...»

Desde luego, las respuestas ponen de manifiesto que, en un porcentaje muy importante, desconocen el significado del término formulación de hipótesis; curiosamente el buen ambiente generado en el aula les lleva a responder con aparente interés, aun con esta limitación. Creemos que, en lugar de hipótesis, la mayoría trata de dar explicaciones. Desde esta perspectiva, se observa que utilizan reiteradamente razonamientos corpusculares.

Habría que señalar que el aprendizaje de este contenido procedimental, como el de los restantes, no se realiza «por casualidad». Por lo tanto, si queremos que los estudiantes lo aprendan, habrá que realizar intervenciones intencionadas que tengan presentes las características científicas del procedimiento, el contexto de aplicación y, por supuesto, las exigencias y prerrequisitos necesarios para su conocimiento (Pro, 1998). En concreto, el alumno se debe «acostumbrar» a realizar conjeturas, predicciones... en el proceso de construcción de su conocimiento como paso previo para aprender la emisión de hipótesis. Pero, además, necesita un marco teórico sólido en el que apoyarla.

\section{b) Respecto al ítem 2p: Diseña una experiencia para comprobar la hipótesis}

- Hubo muchos (12/43) que no contestaron, lo que parece lógico ateniéndonos a los resultados de la pregunta anterior. De los que lo hicieron, consideramos que veintiocho plantean realmente un diseño.

- Un grupo (10/28) hicieron un diseño bastante aceptable, ya que hacían referencia a elementos fundamentales: repetición de las medidas, posibilidad real de llevarla a cabo, distancia suficientemente grande para que el tiempo sea medible con una cierta precisión, etc.:

«Se colocan dos personas a un quilómetro de distancia. Primero en invierno, con el viento a favor y con el viento en contra, se probaría para ver si se oyen el uno al otro; y luego, en las demás estaciones, con el viento a favor y en contra, y así probaríamos con qué estación y posición frente al viento captaríamos mejor la voz de la otra persona.»

«Dos personas a la misma distancia una de otra, una da un grito en sentido contrario al viento, que lleva una velocidad de $60 \mathrm{~km} / \mathrm{h}$ y, luego lo haría al revés, la persona que grita, con la misma intensidad que antes y de espaldas al viento que lleva la misma velocidad, y la otra persona compararía. Esta prueba la haría un día de mucho calor y otro de mucho frío y con las mismas condiciones.»

- Otro grupo (10/28) realizaron un diseño que sólo se centraba en la relación entre el tiempo de escucha y la dirección de la velocidad del tiempo:

«Cuando vas por la calle y el viento viene en contra y le gritas a una persona, no te oye si estás bastante lejos; pero, si el viento viene a tu favor, la persona a la que le has gritado te escucha, aunque esté más lejos que antes.»

«Una persona se pone a cien metros con un gran ventilador detrás. Si habla, las ondas serán ayudadas por el ventilador, después se pone de cara al ventilador y se oye como si la voz te la cortaran.»

«Irse a un descampado que tenga más de 1 quilómetro de largo, señalar un quilómetro de distancia y, en medio, entre estos dos puntos colocar un pañuelo para ver la dirección del viento y, cuando haya el suficiente viento, gritar para que el viento esté a favor de las ondas del que grite.»

- Los demás (8/28) hicieron diseños centrados en la estación del año o describieron un ejemplo; esto suele ser una forma habitual de contestar en este tipo de cuestiones:

«Dos personas, gritando en las diferentes épocas del año. Si en invierno se oye más que en verano, será cierto.»

«Cuando un corredor de velocidad tiene el viento a favor, las marcas serán inferiores porque su cuerpo es empujado y sufre una ayuda del viento.»

Podemos afirmar, a la vista de las respuestas, que muchos saben lo que quieren hacer, son capaces de delimitar las variables fundamentales y que la mayoría de los diseños tienen visos de poderse llevar a la práctica. En cambio, se observa también falta de sistematización a la hora de plantearlos, ya que se conforman con una descripción superficial o incompleta. ¿Es que no se les plantea nunca este tipo de preguntas?

Pero, además, los alumnos utilizan para el diseño modelos interpretativos sobre la propagación del sonido en un medio material y, como hemos podido percibir, coincidentes con los usados en otros ítems de las pruebas. Nos parece muy interesante la persistencia de creencias o conocimientos en diferentes contextos o ante diversos interrogantes.

\section{c) Respecto al ítem 3p: Problema del campo}

- Un gran número (35/43) dieron una respuesta, aunque en algunos casos (6/43) no respondían realmente a lo que se preguntaba.

- Un grupo (8/29) realizaron aportaciones interesantes: conocimiento del valor aproximado de la velocidad del 
sonido en el aire, aplicación del método usado por los agricultores, constatación de la existencia de diferentes velocidades de propagación para la luz y el sonido, utilización de ecuaciones representativas del movimiento... Parecen ideas aún dispersas y que requieren una cierta clarificación y ordenación, pero también ponen de manifiesto que no partimos de la «nada» en la enseñanza del sonido:

«Sí, podría ser, porque la velocidad del sonido es de 300 $\mathrm{m} / \mathrm{s}$ aproximadamente; entonces, si transcurre en tres segundos desde que se ve el rayo hasta que se escucha se puede saber que está a un quilómetro de distancia.»

«Sí es perfecta, porque el sonido que viaja tarda un cierto tiempo en llegar al tímpano; entonces, si vemos la luz del relámpago donde está la tormenta, el trueno ya se ha producido, pero el sonido tarda en llegar un cierto tiempo. Entonces, con un reloj, midiendo el tiempo que tarda en oírse el trueno, se puede saber el tiempo que va a tardar en llegar la tormenta o a cuanta distancia se encuentra.»

«Sí, es correcto. Si el relámpago va a la velocidad de la luz no habrá diferencia de tiempo. A partir de ahí, cuenta el tiempo que tarda en oírse el trueno, y la distancia sería multiplicando el tiempo por la velocidad del sonido.»

- Los demás (21/29) dieron una respuesta que no llegamos a comprender; no sabemos si por problemas de comunicación o, como hemos comentado, por el hábito de «responder sin decir nada»:

«Yo pienso que sí, porque las ondas del sonido van más lentas que la luz, y porque tú, viendo el rayo, no puedes saber donde ha caído, y por eso hacen ese procedimiento y dicen: "Pues, está a tantos quilómetros de distancia."»

«Sí, porque, si es un hecho comprobado, es verdad. Y la gente, cuando oye el relámpago y cuenta los segundos, espera a que suene otro, y, si desde el primer relámpago hasta el segundo pasan 10 segundos, por ejemplo, y del segundo relámpago al tercero pasan 15 segundos, quiere decir que la tormenta se está alejando. Si es al contrario, es que se está acercando cada vez más. Lo dividen luego entre 3 para saber a cuentos quilómetros está la tormenta.»

«Yo creo que puede ser correcto - para una vez que ya lo saben- ya saben el tiempo que tienen para preparar y fortalecer la casa o el ganado o cualquier otra cosa.»

«Sí, porque desde el punto de vista científico es algo que se comprueba, y es cierto.»

«Puede ser un procedimiento no muy perfecto, pero el método es muy bueno y la medida es lo que no es muy verdadera...»

Nos gustaría resaltar el poco uso que han hecho, en general, del aparato matemático en sus respuestas. Así hemos encontrado que, en algunos casos, es una consecuencia directa de las dificultades que han podido tener para la identificación del problema. En otros, han intentado «aplicar alguna fórmula» pero no han sabido «poner los datos» o no la han recordado correctamente. Incluso, muchos han reflejado sus limitaciones en la realización de operaciones aritméticas. Lo realmente curioso es el contraste entre estos resultados y el aparente énfasis que los profesores ponen en la enseñanza de la resolución de ejercicios numéricos.

\section{d) Respecto al ítem 4p: Diseño de experiencia de la piedra}

- Bastantes (18/43) no contestaron -porcentaje sensiblemente mayor que el del ítem $2 \mathrm{p}-$, lo que ratifica la falta de hábito para responder a este tipo de preguntas. De los que respondieron (25/43), cuatro hicieron un diseño incompleto aunque hacían referencia a algunos de los elementos que se pueden considerar fundamentales (repetición de las medidas, posibilidad real de llevarla a cabo, etc.):

«Se pone un barquito encima del agua, después se tira la piedra un poco alejada del barquito; si el barco empieza a subir y bajar, es que se ha producido una onda (acompañándose el texto con un dibujo).»

- El resto se centró en nombrar alguna característica de las ondas, pero sin hacer un diseño propiamente dicho:

«Sí, se producen ondas que son unos circulitos pequeños que salen de donde ha caido el objeto.»

«Sí, se produce, porque la piedra al chocar con el agua produce ruido, y ese ruido se desplaza en ondas a través del agua (por eso hace círculos cuando tiramos la piedra).»

«Si tiras una china a un vaso lleno de agua, verás que el agua producirá unas ondas al haber una vibración...»

Aunque desde el punto de vista de los contenidos procedimentales no es posible extraer mucha más información dada la calidad de las respuestas -a veces teníamos la sensación de que no entendían lo que les planteábamos, creemos que hay otros aspectos que resultan interesantes. Por ejemplo, nos llama la atención que la mayoría de los alumnos, cuando hablan de ondas, está pensando en el sonido, olvidándose de las demás; por eso contestan intentando demostrar que lo que se ha producido en el agua es una onda sonora. Esto refuerza algunas de las ideas apuntadas en otros ítems de las pruebas.

En cualquier caso, los resultados obtenidos en esta prueba se pueden considerar poco satisfactorios. Podría ser que la dificultad conceptual de esta parte de la asignatura y la escasa atención recibida influyera decisivamente en la resolución de este tipo de cuestiones. Sin embargo, creemos que el problema es una consecuencia de la poca importancia que realmente le asignan los profesores a este tipo de contenidos en las clases de ciencias. 


\section{DESCRIPCIÓN DE LOS RESULTADOS POR ESQUEMAS}

Además de hacer una descripción detallada de las respuestas que dieron en ambas pruebas, nos parece necesario establecer y describir cuáles son los esquemas o estructuras de razonamiento que subyacen en sus contestaciones. Para ello hemos estudiado globalmente las respuestas a diferentes ítems con el fin de tratar de identificarlos, tal como indicamos anteriormente.

\section{Esquemas de las magnitudes ondulatorias}

Los resultados obtenidos aparecen en la tabla I; los esquemas correspondientes se representan en la figura 1.

Se puede observar que hay alumnos que no responden o que de sus respuestas no es posible inferir un esquema (7/43). También habría que resaltar que un número importante (18/43) utiliza los esquemas $M O-1, M O-1 a$ y $M O-1 b$, que son los más intuitivos o anecdóticos de los descritos. El más avanzado de los encontrados -el $M O-5$ - sólo es utilizado por un alumno; en éste, es posible apreciar la existencia de un conocimiento estructurado, aunque evidentemente se puede completar y ampliar.

En los primeros esquemas interpretativos, que hemos denominado $M O-1, M O-1 a$ y $M O-1 b$, no se percibe una concepción global, ya que simplemente se limitan a relacionar un movimiento ondulatorio con una de sus magnitudes características. Así, vemos que en el $M O-1$ sólo hablan de la frecuencia identificándola como «el sitio donde se puede sintonizar una onda»; en el $M O-1 a$ confunden la longitud de onda con el alcance; y en el $M O-1 b$, además, no encuentran ninguna diferencia entre frecuencia y longitud de onda. No obstante, reconocen explícitamente que existen diferentes tipos de ondas.

En el esquema $M O-2$ aparecen definidas tanto la frecuencia como la longitud de onda, pero, al igual que ocurría en los anteriores, las identifican con la sintonía y con el alcance. En este caso, sí se da una cierta diferenciación al estar definidas de distinta manera; las referencias a la amplitud siguen siendo confusas.

En los esquemas $M O-3$ y $M O-3 a$ se aprecia que son capaces de especificar diferentes tipos de ondas y, ade- más, tienen una concepción de la frecuencia próxima a la científica. No obstante, en el MO-3 desconocen otras magnitudes igualmente representativas de las ondas como la longitud de onda, la velocidad de propagación o la amplitud. En los casos correspondientes al $M O-3 a$, además de identificar la frecuencia con el número de ondas por segundo o con algunas de sus unidades, persiste la idea de que la longitud de onda es el alcance. También hay que resaltar que continúan las confusiones con respecto a la amplitud.

La característica común a los esquemas $M O-4, M O-4 a$ y $M O-4 b$ es la utilización explícita de otras magnitudes propias de las ondas (no sólo la frecuencia o la longitud de onda). En todos los casos parece que hay un conocimiento, por lo menos intuitivo, de lo que son las ondas; aun así, persiste el problema de las concepciones equivocadas o de relaciones erróneas desde una perspectiva científica. Por ejemplo, observamos confusiones entre frecuencia y velocidad de propagación $(M O-4)$, o entre la amplitud y la frecuencia, o la longitud de onda $(M O-4 a)$. Hay quienes reconocen qué es la frecuencia, pero persisten en las confusiones entre la amplitud y la longitud de onda, como ocurre con $M O-4 b$.

En el esquema $M O-5$, además de reconocer ejemplos de ondas, es capaz de definir correctamente la longitud de onda y la frecuencia. Probablemente exista una concepción bastante acertada de las otras magnitudes, pero no las utilizan en sus razonamientos ante las preguntas planteadas.

A la vista del análisis realizado para determinar los esquemas sobre magnitudes ondulatorias, podemos decir:

- Consideran las ondas siempre como transversales, se centran casi exclusivamente en el sonido y no poseen lógicamente una visión global e integrada de lo que es una onda.

- En la mayoría de los casos se limitan a establecer una o dos de sus magnitudes características, una de las cuales suele ser la frecuencia

- Se aprecia también una confusión terminológica: entre período y frecuencia, entre longitud de onda y frecuencia, o entre longitud de onda y amplitud; en muchos

\begin{tabular}{|c|c|c|c|c|c|c|c|c|c|c|c|}
\hline Esquema & NO & 1 & $1 \mathrm{a}$ & $1 b$ & 2 & 3 & $\mathbf{3 a}$ & 4 & $\mathbf{4 a}$ & $4 b$ & 5 \\
\hline Frecuencia & 7 & 9 & 5 & 4 & 5 & 2 & 2 & 2 & 3 & 3 & 1 \\
\hline Porcentaje & $16 \%$ & $21 \%$ & $12 \%$ & $9 \%$ & $12 \%$ & $5 \%$ & $5 \%$ & $5 \%$ & $7 \%$ & $7 \%$ & $2 \%$ \\
\hline
\end{tabular}


Figura 1
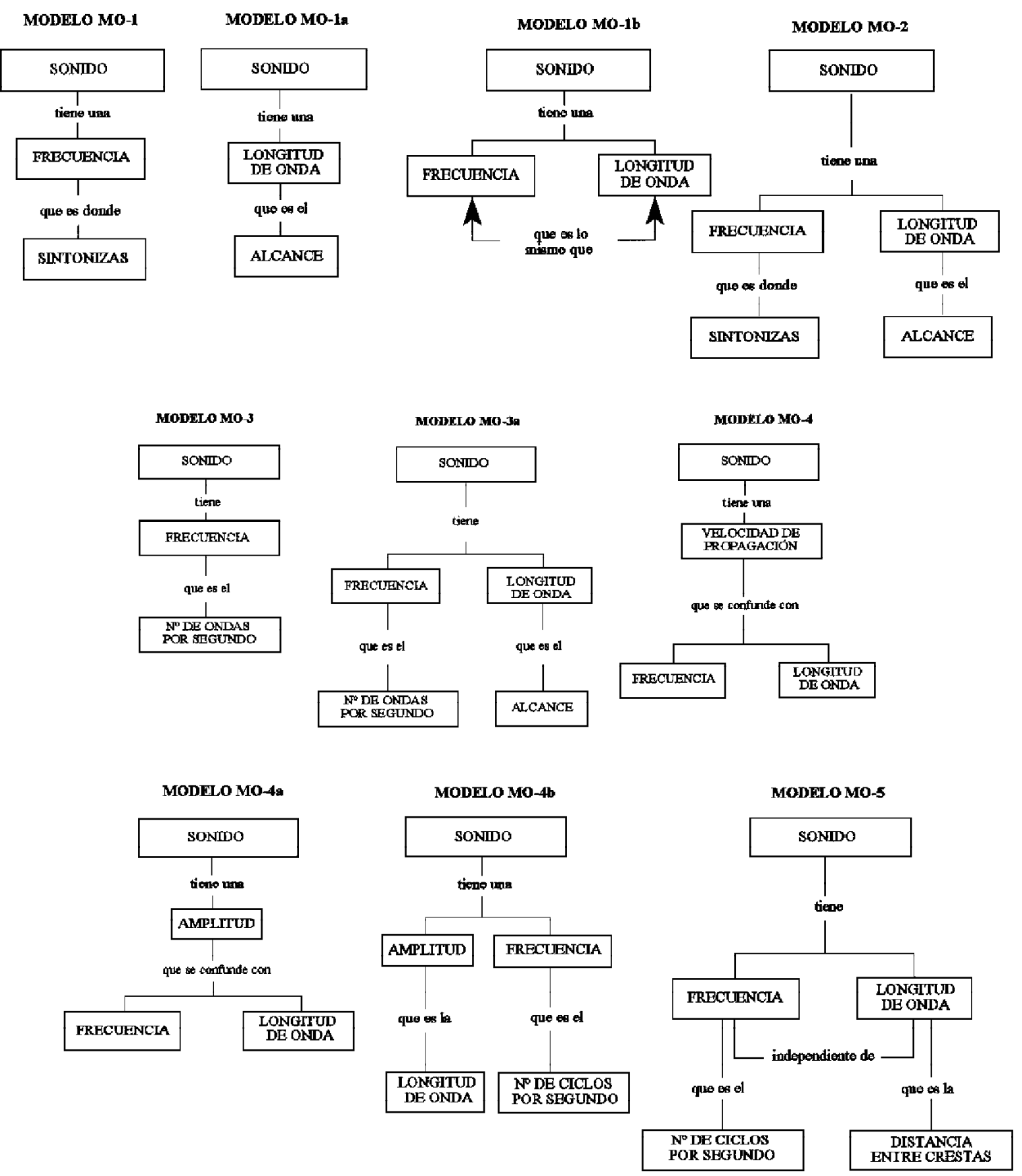

casos, identifican la longitud de onda con el alcance, o la frecuencia con la sintonía de la radio.

- También es frecuente el establecimiento de relaciones incorrectas entre variables, como con la velocidad de propagación y la amplitud.

\section{Esquemas de la propagación del sonido}

Los resultados obtenidos aparecen en la tabla II; los esquemas correspondientes aparecen representados en la figura 2. 
Figura 2
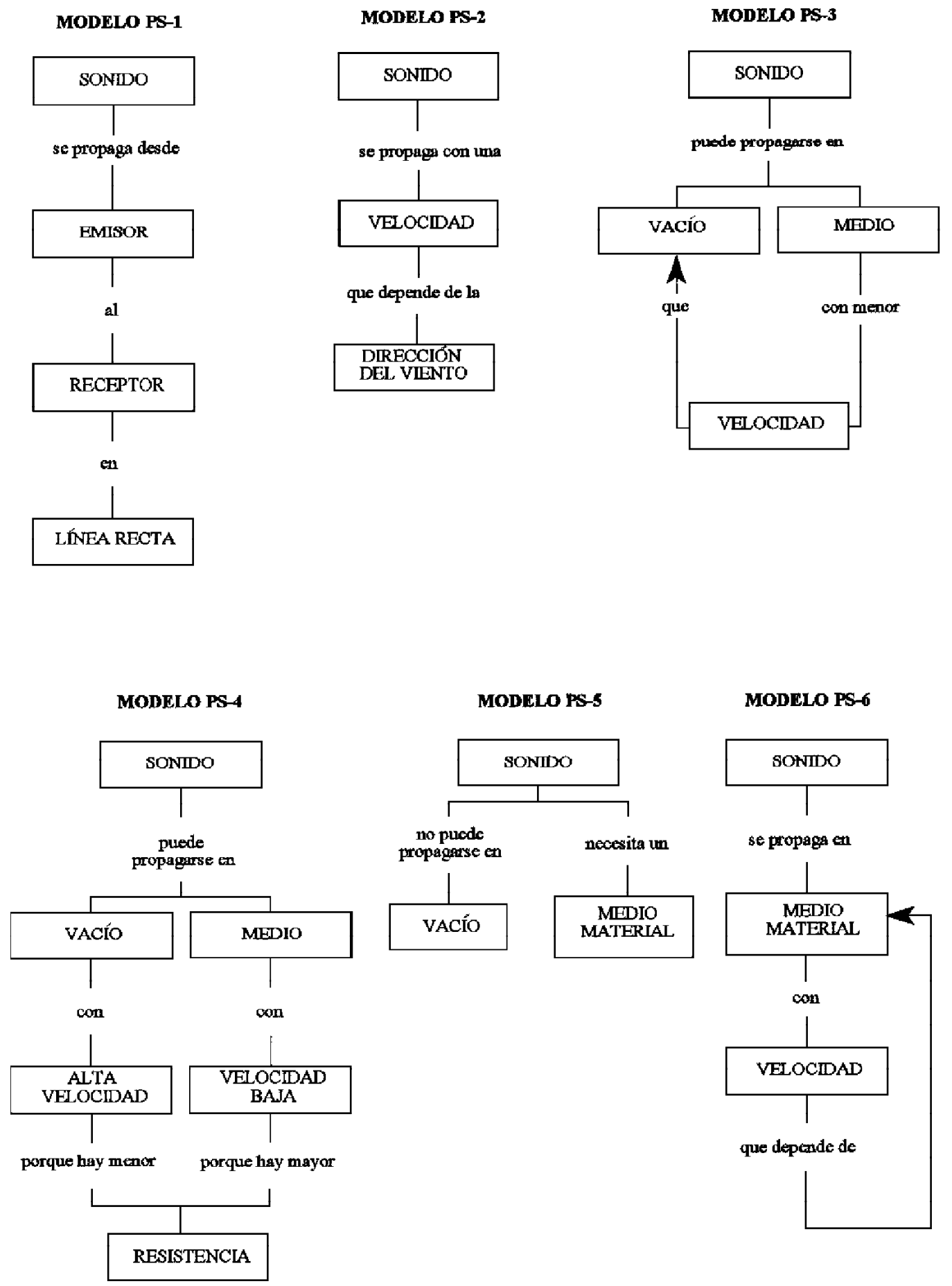

MODELO PS-6

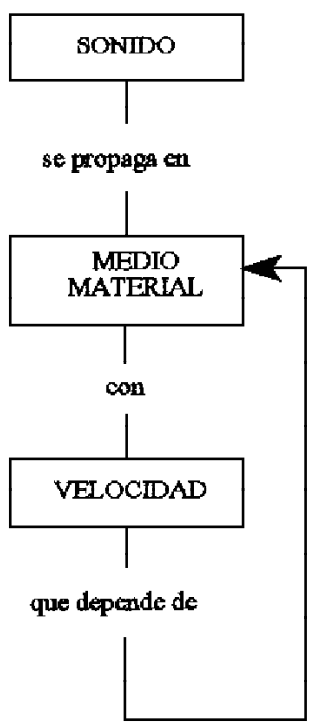

Se puede observar que, en este caso, hay un menor número de alumnos (3/43) que no responden o que de sus respuestas no es posible establecer un esquema interpretativo. Habría que resaltar que 21 (prácticamente la mitad) utilizan el $P S-4$ y que 9 utilizan los esquemas más intuitivos o anecdóticos de los descritos ( $P S-1$ y $P S-2$ ). Por otro lado, habría que resaltar que el esquema más avanzado, el PS-6, sólo es utilizado por uno de ellos. 
En el primer esquema, que hemos denominado $P S-1$, hemos incluido una respuesta que se basa en la utilización de conocimientos cinemáticos un tanto distorsionados. No responde cuando se le plantea sobre la necesidad o no de un soporte material para la propagación y sólo utiliza reiteradamente que se propaga del emisor al receptor. En el $P S-2$ tampoco contestan, o lo hacen de forma confusa, cuando se les plantea la influencia del medio en la propagación.

En el $P S-3$ se incluyen contestaciones que hacen alusión a que la velocidad de propagación depende del medio, aunque persiste la concepción de que ésta es más pequeña que en el vacío. Las respuestas incluidas en el $P S-4$ siguen considerando que depende del medio y que en el vacío es mayor pero, además, incluyen una explicación a dicha afirmación en términos de mayor o menor resistencia al desplazamiento.

En el PS-5 las respuestas incluidas consideran la necesidad de un medio material para la propagación del sonido; es decir, ponen de manifiesto explícitamente que no hay propagación en el vacío. No incluyen otras consideraciones acerca de la velocidad.

La respuesta incluida en el PS-6 indica explícitamente que no es posible la propagación del sonido sin un medio material y que la velocidad depende de dicho medio, aunque no es capaz de determinarla numérica y cualitativamente; de hecho, no puede diseñar una experiencia para demostrar que es constante.

A la vista del análisis realizado para determinar los esquemas sobre la propagación del sonido, podemos decir:

- En general, no consideran que sea necesaria la existencia de un medio para que se propague el sonido, así como que su velocidad de propagación depende de que el medio le oponga mayor o menor dificultad a su avance, lo que proyecta una concepción corpuscular del mismo.

- Consideran la existencia de una dirección privilegiada en la propagación del sonido, que suele ser la del emisor al receptor.

- A pesar de que los esquemas interpretativos son más completos que en el de las magnitudes ondulatorias, se detectan pocas relaciones cruzadas entre conceptos, lo que parece responder a la escasez de conocimientos estructurados

\section{Esquemas de la reflexión del sonido}

Los resultados obtenidos aparecen en la tabla III; los esquemas correspondientes se representan en la figura 3 .

Hubo, como en otros casos, alumnos (8/43) con los que no fue posible establecer un esquema interpretativo. Habría que destacar que los más utilizados han sido $R S-1$ y $R S$-2; como elemento positivo señalaríamos el uso del $R S-5$ por un grupo importante de estudiantes.

En el primer esquema, que hemos denominado $R S-1$, se incluyen aquellas respuestas en las que se considera que el eco es un fenómeno de amortiguación del sonido, producidos al chocar contra una superficie.

Los $R S-2$ y $R S-2 a$ tienen en común que no consideran que el eco sea un fenómeno de amortiguación del sonido, sino de reflexión. En sus justificaciones utilizan términos de cierta cotidianidad y no demasiado científicos; así, por ejemplo, en el $R S-2$ se habla de onda devuelta y en el $R S$ - $2 a$, dentro de un contexto de lenguaje cotidiano, se deja entrever una dependencia no sólo respecto a la emisión sino también respecto a la superficie de reflexión (la montaña).

En el $R S-3$ se incluyen las respuestas en las que explícitamente se reconoce el eco como un fenómeno de reflexión del sonido y se da una justificación más cercana a la concepción científica. No obstante, no se hace alusión a que el fenómeno sólo se produce en determinadas situaciones; parece como si siempre se produjera eco.

Se aprecia en las respuestas del $R S$-4 no sólo el reconocimiento del fenómeno sino que se indica explícitamente que su producción sólo se da en determinadas circunstancias. La alusión a la superficie de reflexión se realiza sin ambigüedades, aunque no se especifiquen las condiciones, ni se hable de otros aspectos de singular importancia para la conceptualización de este término.

En el $R S-5$ es posible apreciar el reconocimiento de la existencia de una onda reflejada que llega al receptor con desfase respecto a la emitida; es decir, son casos particulares de una propiedad del sonido: la reflexión. Lógicamente no se hace ninguna alusión a las leyes de la reflexión pero, desde luego, la idea es mucho más elaborada que las anteriores.

Tabla II

\begin{tabular}{|c|c|c|c|c|c|c|c|}
\hline Esquema & NO & $\mathbf{1}$ & $\mathbf{2}$ & $\mathbf{3}$ & $\mathbf{4}$ & $\mathbf{5}$ & $\mathbf{6}$ \\
\hline Frecuencia & 3 & 1 & 8 & 2 & 21 & 7 & 1 \\
\hline Porcentaje & $7 \%$ & $2 \%$ & $19 \%$ & $5 \%$ & $49 \%$ & $16 \%$ & $2 \%$ \\
\hline
\end{tabular}


Figura 3
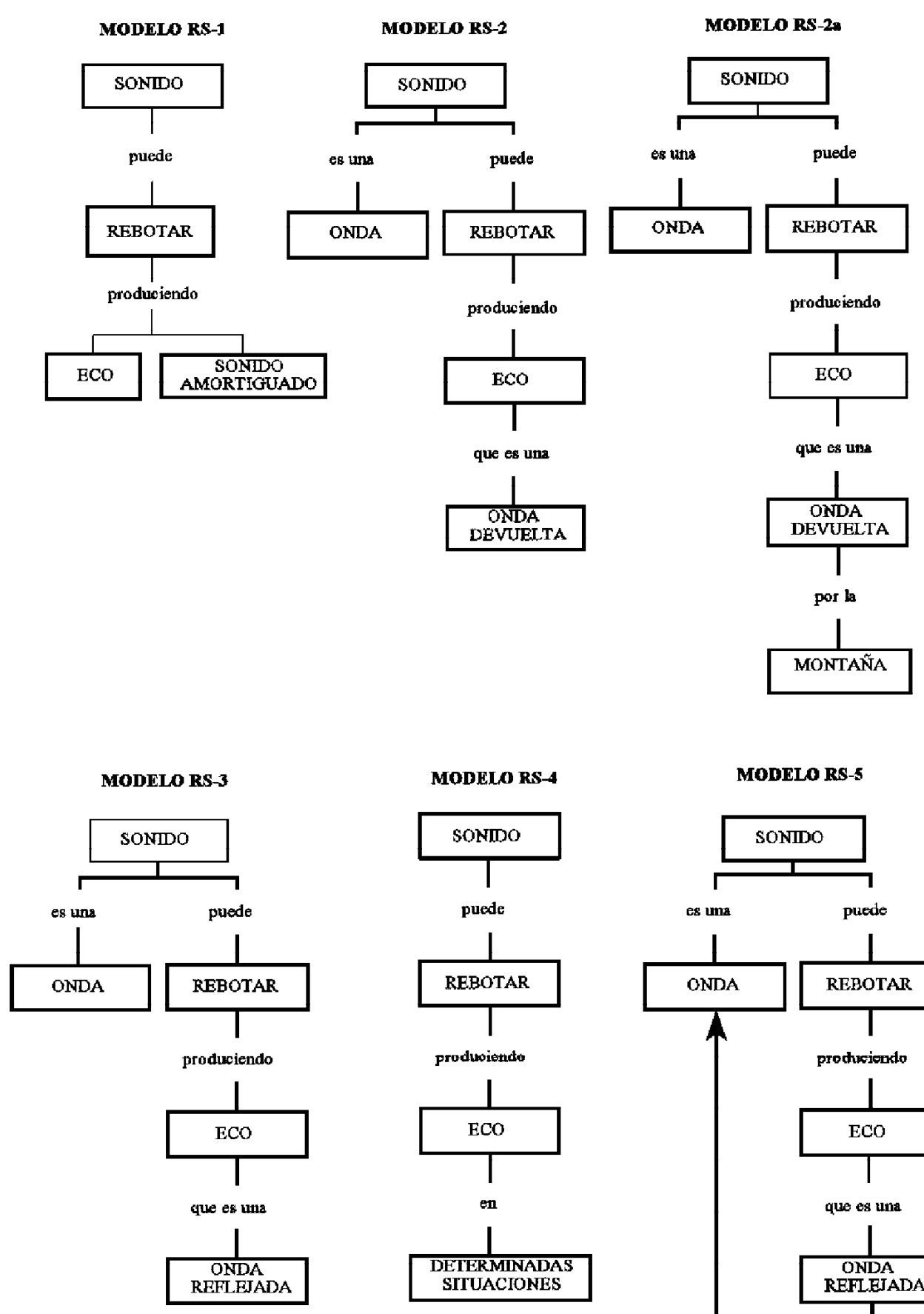

MODELO RS-4

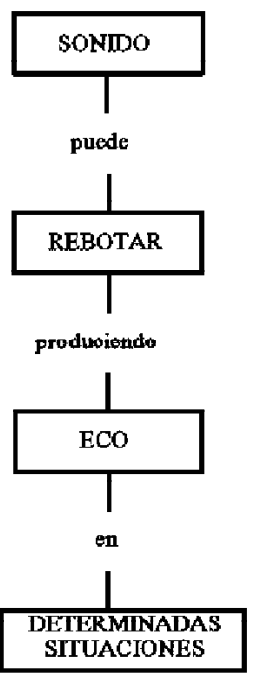

MODELO RS-5

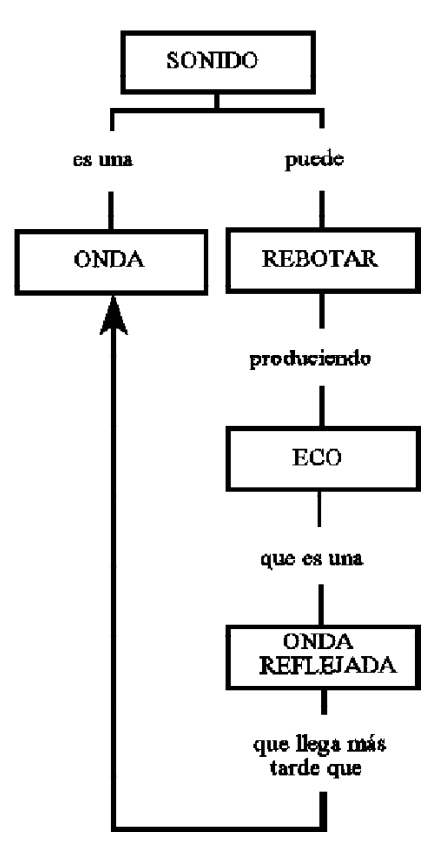


Tabla III

\begin{tabular}{|c|c|c|c|c|c|c|c|}
\hline Esquema & NO & $\mathbf{1}$ & $\mathbf{2}$ & $\mathbf{2 a}$ & $\mathbf{3}$ & $\mathbf{4}$ & $\mathbf{5}$ \\
\hline Frecuencia & 8 & 12 & 7 & 1 & 4 & 4 & 7 \\
\hline Porcentaje & $19 \%$ & $28 \%$ & $16 \%$ & $2 \%$ & $9 \%$ & $9 \%$ & $16 \%$ \\
\hline
\end{tabular}

A la vista de los resultados referidos a los esquemas sobre la reflexión del sonido:

- Es posible apreciar que la mayoría de los esquemas son bastante sencillos y con pocas relaciones cruzadas, lo que parece indicar una concepción bastante elemental de este fenómeno.

- Son fundamentalmente descriptivos y, en la mayoría de los casos, se limitan a comentar características o propiedades, pero con muy pocas justificaciones de lo que afirman.

- En todos los esquemas, desde los más sencillos a los más complicados, aparece el eco, lo que parece sugerir la gran importancia que le dan a este fenómeno, posiblemente por ser el más observable para ellos. No obstante, algunos lo identifican con la reverberación, constituyendo lo que hemos denominado eco doméstico.

- También se aprecia, en los esquemas de los alumnos de la investigación, que la reflexión del sonido parece producirse sin ninguna ley que la regule.

\section{IMPLICACIONES DIDÁCTICAS}

La experiencia realizada pone de manifiesto la existencia de pequeñas estructuras de razonamiento que condicionan o favorecen el aprendizaje de los alumnos en estos niveles educativos. Parece, pues, lógico que, desde una concepción constructivista, se realicen intervenciones intencionadas que permitan la modificación, sustitución o ampliación de las mismas para aproximarlas a esquemas más útiles para las necesidades sociales y formativas de cualquier ciudadano.

Aunque es evidente la precariedad de los esquemas encontrados, hay que hacer notar que su adquisición no ha sido realizada exclusivamente en el marco institucional y que, por lo tanto, son también fruto de un proceso autónomo, no reglado y basado en los conocimientos que les aportan sus experiencias cotidianas. En estas circunstancias, nosotros valoramos muy positivamente algunas respuestas y razonamientos que apoyan la idea de que las capacidades de los estudiantes no están suficientemente explotadas en las clases de ciencias.

Pero, centrándonos en aspectos más concretos del estudio del sonido, podemos señalar:
- Sería necesario establecer la diferencia existente entre onda, emisor y receptor, que tienden a confundir, utilizando profusamente ejemplos muy diversos.

- Habría que ampliar su visión más allá de las ondas sonoras, a las que consideran «las ondas por excelencia»; contradictoriamente con ello, no establecen relaciones entre las cualidades de un sonido y las magnitudes características de las ondas.

- Tendríamos que eliminar la concepción sesgada de las ondas, que las «limita» a las transversales y a las materiales.

- Parece necesario clarificar sus conocimientos sobre las magnitudes características de las ondas; hay que observar un especial cuidado con las actividades en las que aparezcan los conceptos de frecuencia, amplitud y longitud de onda.

- Probablemente el conocimiento convencional o exclusivamente matemático impide la conceptualización de las magnitudes ondulatorias; habría que recuperar la identificación física.

- Se aprecia un gran desconocimiento sobre el vacío y la composición de la materia, y concepciones equivocadas sobre la energía, que pueden condicionar otros aprendizajes.

- Habría que identificar y diferenciar fenómenos como la reflexión, amortiguación, refracción e interferencias, pues tenemos la impresión que no compartimos con ellos los mismos significados, ni las mismas experiencias.

- Habría que aprovechar sus experiencias extraescolares e incluir, en la selección de contenidos, conocimientos sobre audición, contaminación... que aprovechen sus propias vivencias externas al aula y que les demuestren la utilidad de estos contenidos.

- En relación con los contenidos procedimentales, el tema permite incluir el diseño de experiencias, el control y exclusión de variables, y la formulación de predicciones (la emisión de hipótesis está muy mediatizada por carencias metodológicas de los niveles anteriores). En cualquier caso, no hay que olvidar que hay que emplear tiempo para enseñarlos, aun a costa de otros contenidos, y que su aprendizaje es lo suficientemente complejo para «no aprenderlos a la primera». 
- Se observa el uso del modelo corpuscular en los razonamientos sobre el sonido; habría que establecer las diferencias con el ondulatorio pero sin perder de vista que el alumno valore su eficacia en la aplicación a situaciones reales.

En cualquier caso, el trabajo nos ha sugerido muchos interrogantes: ¿Qué otros esquemas tienen los alum-

\section{REFERENCIAS BIBLIOGRÁFICAS}

CLOUGH, E. y DRIVER, R. (1986). A study of consistency in the use of students' conceptual frameworks across different task contexts. Science Education, 70, pp. 437-496.

DRIVER, R. (1988). Un enfoque constructivista para el desarrollo del currículo en ciencias. Enseñanza de las Ciencias, 6, pp. 109-120.

EINSTEIN, A. e INFELD (1961). The Evolution of Physics. Op. cit. por Serway, R., Física, pp. 696-697. México: Interamericana.

GIORDAN, A. (1989). De las concepciones de los alumnos a un modelo de aprendizaje alostérico. Investigación en la Escuela, 8, pp. 3-14.

HODSON, D. (1985). Philosophy of science and science education. Studies in Science Education, 12, pp. 25-37.

KEMPA, R. (1991). Student's learning difficulties in Science. Causes and possible remedies. Enseñanza de las Ciencias, 4 , pp. $99-110$.

LLORENS, J.A., DE JAIME, M.C. y LLOPIS, R. (1989). La función del lenguaje en un enfoque constructivista del aprendizaje de las ciencias. Enseñanza de las Ciencias, 7, pp. 111-119.

MARÍN, N. y JIMÉNEZ, E. (1992). Problemas metodológicos en el tratamiento de las concepciones de los alumnos en el contexto de la filosofía e historia de las ciencias. Enseñanza de las Ciencias, 10, pp. 335-339.

LINDER, C. (1993). University physics students' conceptualizations of factors affecting the speed of sound propagation. International Journal Science Education, 15, pp. 655-662.

LINDER, C. y ERIKSON, G. (1989). A study of tertiary physics students' conceptualizations of sound. International Journal Science Education, 11, pp. 491-501.

LÓPEZ, M.A., ORENES, J.L. y PRO, A. (1997). Condiciones previas para el aprendizaje del sonido en la ESO, en Jiménez y Wamba, Avances en la didáctica de las ciencias experimentales, pp. 163-171. Huelva: Universidad de Huelva.

MAURINES, L. (1992a). Spontaneus reasoning on the propagation of visible mechanical signals. International Journal Science Education, 14, pp. 279-293. nos de estos niveles educativos? ¿Cómo se han formado? ¿Cómo se pueden modificar, ampliar y sustituir de forma significativa? ¿Tienen los alumnos esquemas interpretativos en otros ámbitos de las ciencias? ¿Cómo «enganchar» este tipo de hallazgos con enfoques de enseñanza como CTS?... Habrá que seguir investigando.

MAURINES, L. (1992b). Los estudiantes y la propagación de las señales mecánicas: dificultades de una situación de varias variables y procedimientos de simplificación. Enseñanza de las Ciencias, 10, pp. 49-57.

NOVAK, J. (1988). Constructivismo humano: un consenso emergente. Enseñanza de las Ciencias, 6, pp. 83-94.

OSBORNE, P. y WITTROCK, M. (1985). The generative learning model and its implications for science education. Studies in Science Education, 12, pp. 59-87.

OTERO, J. (1990). Variables cognitivas y metacognitivas en la comprensión de textos científicos: el papel de los esquemas y el control de la propia comprensión. Enseñanza de las Ciencias, 8, pp. 17-22.

PERALES, J. (1997). Escuchando el sonido: concepciones sobre acústica en alumnos de distintos niveles educativos. Enseñanza de las Ciencias, 15, pp. 233-247.

POSNER, G., STRIKE, K., HEWSON, P. y GERTZOG, W. (1982). Accomodation of scientific conception: toward a theory of conceptual change. Science Education, 66, pp. 211-227.

POZO, I. (1992). El aprendizaje y la enseñanza de hechos y conceptos, en Coll, C. et al., Desarrollo psicológico y educación. Psicología de la Educación. Madrid: Alianza.

POZO, I., SANZ, A., GÓMEZ, M.A. y LIMÓN (1991). Las ideas de los alumnos sobre la ciencia: una interpretación desde la psicología cognitiva. Enseñanza de las Ciencias, 9, pp. 83-94.

PRO, A. (1998). ¿Se pueden enseñar contenidos procedimentales en las clases de ciencias? Enseñanza de las Ciencias, 16, pp. 21-41.

SAURA, O. (1996). Aprendizaje de esquemas conceptuales y de contenidos procedimentales en el estudio de las ondas, del sonido y de la luz, a partir de una propuesta de enseñanza con un enfoque constructivista. Un trabajo experimental en el ámbito de la educación secundaria. Tesis doctoral. Universidad de Murcia.

SEARS, F. (1986). Física universitaria. México: Fondo Educativo Interamericano.

SERWAY, R. (1985). Física. México: Interamericana. 